http://doi.org/10.35784/iapgos.2080

\title{
TORQUE MEASURING CHANNELS: DYNAMIC AND STATIC METROLOGICAL CHARACTERISTICS
}

\author{
Vasyl V. Kukharchuk ${ }^{1}$, Valerii F. Hraniak ${ }^{1}$, Samoil Sh. Katsyv ${ }^{1}$, Volodymyr S. Holodyuk ${ }^{2}$ \\ ${ }^{1}$ Vinnitsa National Technical University, Vinnitsa, Ukraine, ${ }^{2}$ LLC KNESS RnD CENTER, Vinnitsa, Ukraine
}

Abstract. A formalized method for obtaining the analytical dependencies for the evaluation of the main dynamic and static metrological characteristics of a torque measuring channel with a capacitance sensor operating under the regulation of a microcontroller is proposed. The static and dynamic characteristics of such a typical torque measuring channel based on a capacitance force sensor were evaluated.

Keywords: measurement, electric motor, dynamic and static metrological characteristics, measuring lever, effort sensor, measuring channel

\section{KANALY POMIAROWE MOMENTU OBROTOWEGO: DYNAMICZNE I STATYCZNE CECHY METROLOGICZNE}

Streszczenie. Zaproponowano sformalizowana metode uzyskiwania zależności analitycznych do oceny głównych dynamicznych $i$ statycznych charakterystyk metrologicznych kanatu pomiaru momentu obrotowego z czujnikiem pojemnościowym dziatajacym pod kontrola mikrokontrolera. Ocenie poddano charakterystykę statyczną i dynamiczna typowego kanalu pomiaru momentu obrotowego opartego na czujniku sity pojemnościowej.

Słowa kluczowe: pomiar, silnik elektryczny, dynamiczne i statyczne charakterystyki metrologiczne, dźwignia pomiarowa, czujnik wysiłku, kanał pomiarowy

\section{Setting the task}

To measure torque, $M_{O}$, the methods used most frequently are based on its transformation into mechanical relocation of a sensor's elastic element designed in the form of a continuous or a flat shaft (torsional), coiled springs, membrane etc. Using a measuring lever $L$ long, torque $M_{O}$ is transformed into force

$Q$, under the action of which the sensor's elastic element transforms it into mechanical (linear or angular) displacement, which is in its turn transformed into an electric value using a sensitive element.

The simplest and most widespread method for the measurement of mechanical displacements is tensiometric [6], which employs tensoresistors as the primary measuring transformers of non-electric value $Q$ into electric value $R$, while secondary measuring circles of tensoresistive sensors are normally presented by bridge-type means.

Despite their relatively low precision (with the cumulative error of force measurement ranging from 2 to $3 \%$ ), measurements of high moments $\left(10^{5} \ldots 10^{6} \mathrm{~N} \cdot \mathrm{m}\right)$ are often carried out using torque meters with magnetoelastic measuring transformers distinguished for design simplicity, high reliability and significant output signal power.

Piezoelectric torque meters are based on piezoelectric measuring transformers turning force $Q$ into an electrical charge. The difficulties that occur during the construction of piezoelectric torque meters are conditioned by the electrostatic nature of the charges: their low value, the tendency towards rapid runoff through insulation resistance and the input resistance of the intensifier. The advantages may include high sensitivity and response speed. The reduced error of torque meters with a piezoelectric sensor ranges within 1-2\%.

In capacitance force transducers, membranes are the sensitive elements that transform force $Q$ into plate displacement $d$. At the same time, they may also be used as movable electrodes. The range of torque measurement using capacitance measuring transformers is tens of $N \cdot \mathrm{m}$ with sensitivities of 0.5 to $1.0 \mathrm{pF} / \mathrm{N}$ and initial capacities of tens of $\mathrm{pF}$. The relative error of measurement does not exceed $2 \%$.

The generalized structural diagram of a primary measuring transformer that implements the methods described above is shown in Fig. 1.

Measurement object EM is mounted on the foundation rigidly, and its rotor is constrained with measuring lever ML through effort sensor ES. Such circuits are quite well known. Their variation is only determined by the type of parametric force sensor, in which non-electric value $Q$ is transformed into electrical circuit parameters $R, L, C$. Unfortunately, national and international literary sources currently lack any information on a uniform approach to the construction of a digital measuring torque channel due to the absence of any techniques for analysis of the properties of such measurement means, both for dynamic and static operational modes [3]. Such a situation does considerably restrict the development and implementation of the means for measurement of static, electromagnetic, rotational, actuating and dynamic torques in measurement practice. Therefore the process of testing of electrical machines in "isle mode" and "short circuit" have not been computerized yet, which results in significant time losses, non-conformity of errors of the measurement means with up-to-date requirements, the impossibility of creating information-and-measuring systems and systems for computerized control and technical diagnostics thereof. Hence, the objective of this paper lies in the development of a methodology for obtaining dynamic and static metrological characteristics, and on their basis, construction of digital measuring channels with parametric sensors on the example of a capacitance one.

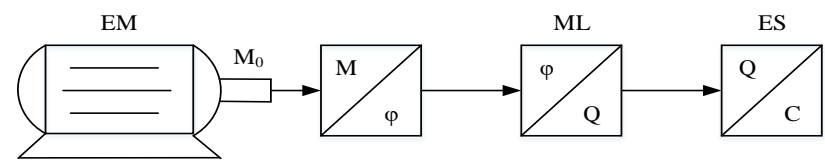

Fig. 1. Generalized structural diagram of a primary measuring transformer

\section{Mathematical model of a measuring transformer in its dynamic mode of operation}

In accordance with the fundamentals of the theory of electromechanical measuring transformation [4, 7], we obtain the differential equation that describe the process of movement of the movable part of the proposed transformers.

During rotation of a solid body (movable part: EM rotor with measuring lever ML) around its radial axis, $J$, on angular acceleration, $\frac{d^{2} \varphi(t)}{d t^{2}}$ equals the sum of the force torques acting on the body, in relation to its own body, i.e.:

$$
J \cdot \frac{d^{2} \phi(t)}{d t^{2}}=\sum_{i=1}^{n} M_{i},
$$

where: $J$ - inertia torque of MT's movable part; $\varphi$ - turning angle of the transformer's movable part; $M$ - torques acting on the transformer's movable part. 
The following torques act on the movable part of the measuring transformer during its movement.

1. The torque representing itself in the general case, $M(t)$.

2. The countertorque determined by the elastic properties of the force sensor:

$$
M_{\Pi P}=-c \cdot \varphi(t),
$$

where: $c=\frac{e \cdot r^{4}}{E \cdot h^{3}}-$ stiffness of the force sensor's membrane, $r$ - membrane radius, $h$ - membrane thickness, $E$ - membrane elasticity module, $e=0.17$

3. Damping torque that equals the product of damping ratio $P$ and the angular velocity of rotation:

$$
M_{3}=-P \cdot \frac{d \varphi(t)}{d t} .
$$

By substituting the values of the torques obtained for (1), we obtain:

$$
J \frac{d \varphi^{2}(t)}{d t^{2}}+P \frac{d \varphi(t)}{d t}+c \cdot \varphi(t)=M(t)
$$

Let us transform (4) into the generally used form

$$
\frac{d^{2} \varphi(t)}{d t^{2}}+2 \cdot \varepsilon \cdot \omega \frac{d \varphi(t)}{d t}+\omega^{2} \cdot \varphi(t)=\frac{M(t)}{J},
$$

where: $\omega=\sqrt{c / J}$ - own frequency of the transformer's free (undamped) oscillations, $\varepsilon=P /(2 \cdot \sqrt{J c})$ - the degree of damping of free oscillations.

In the general case, solution (5) for random input signal $\mathrm{x}$ looks as follows

$$
\varphi(t)=\frac{1}{J} \int_{0}^{t} \frac{1}{\sqrt{1-\varepsilon^{2}} \omega} \times e^{(-\varepsilon \omega x)} \sin \left(\sqrt{1-\varepsilon^{2}} \omega x\right) \times M(t-x) d x .
$$

For static torque ( $M_{O}=$ const $)$, equation (6) can be presented as follows $[1,2,5]$ :

$$
\frac{d^{2} \varphi(t)}{d t^{2}}+2 \varepsilon \omega \frac{d \varphi(t)}{d t}+\omega^{2} \varphi(t)=\frac{M_{O}}{J} .
$$

Having solved (7) in the Maple 13 computer program, we obtain $[1,5]$ :

$$
\varphi(t)=\frac{M_{O}}{c}\left\{1-e^{-\varepsilon \omega t}\left[\begin{array}{c}
\frac{\varepsilon}{\sqrt{1-\varepsilon^{2}}} \times \sin \left(\sqrt{1-\varepsilon^{2}} \omega t\right)+ \\
+\cos \left(\sqrt{1-\varepsilon^{2}} \omega t\right)
\end{array}\right]\right\} .
$$

The characteristic curve $\varphi(t)$ in the dynamic mode of the measuring torque transformer's operation is shown in Fig. 2.

Computer modeling of the $\varphi(t)$ dependency for measuring transformer's movable part was performed with the following parameters:

$$
M_{0}=1 . .25 \mathrm{~N} \cdot \mathrm{m} ; \quad \quad c=5 \cdot 10^{3} \frac{\mathrm{N} \cdot \mathrm{m}}{\mathrm{rad}} ; \quad P=0.5 \frac{\mathrm{N} \cdot \mathrm{m} \cdot \mathrm{s}}{\mathrm{rad}} ;
$$$$
J=9.7 \cdot 10^{-4} \mathrm{~N} \cdot \mathrm{m}^{2} .
$$

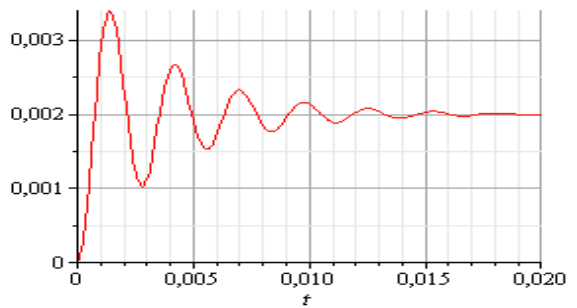

Fig. 2. $\varphi(t)$ dependency

The results obtained establish the duration of the MT's transient process, which determines the potential response speed of the means of torque measurement. The opportunity now arises to establish the dependence of the value of angular deviation of the MT's movable part on the value of torque $M_{0}$ applied thereto, which allows these results to be used when selecting the force sensor's membrane stiffness.

\section{Mathematical model of a measuring transformer in its static mode of operation}

For the static mode of operation in differential equation (7) that describes the dynamic mode of the measuring transformer's operation, let us equate the derivatives to zero and obtain the following transformation equation:

$$
\varphi=\frac{M}{c} \text {. }
$$

Should, for example, a capacitance sensor be used as the ES, then due to elastic properties of its membrane, countertorque to measuring lever $M_{\Pi P}$ displacement will be generated. As a result, torque $M_{O}$ will be transformed into turning angle $\varphi$. Since the membranes of such sensors have a relatively high stiffness, $c$, measuring levers have to deviate by small angle $\varphi$. Since for small angles, $\varphi \cong \sin \varphi$, the dependency between turning angle $\varphi$ and the distance between the plates of the capacitance sensor is determined as follows:

$$
d=k \varphi=\frac{k \cdot M}{c},
$$

where $k-$ the ration of the membrane's measuring transformation.

Let us write the equation of a flat capacitor's transformation, in which plate displacement $d$ is transformed into capacity $C_{M}$. Disregarding the edge effects, the capacity of the flat capacitor is determined as follows:

$$
C_{M}=\frac{\xi_{0} \xi S}{d} .
$$

Let us substitute (11) for $d$ from (10) and obtain the function of the capacitance force sensor's transformation

$$
C_{M}=\frac{\xi_{0} \xi S c}{k M_{O}}
$$

that unambiguously links the initial value of the force sensor's capacity value $C_{M}$ to the input value - rotational torque $M_{O}$.

The static characteristics of such a measuring transformer are non-linear (Fig. 3). In the range of torque variation (from 1 to $25 \mathrm{~N} \cdot \mathrm{m}$ ), the condenser's capacity will change respectively from 1 to 10 microfarad, which is sufficient to construct a digital capacitance meter of high response speed and precision.

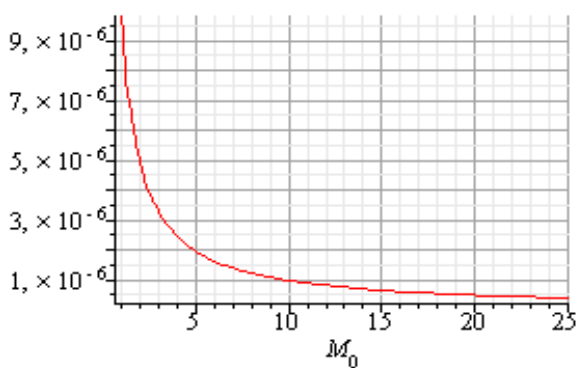

Fig. 3. Static characteristics of measuring transformer

\section{Main static metrological characteristics of torque measuring channel}

In this section, we show a structural diagram of a torque measuring channel based on a capacitance torque sensor and digital capacity meter [8] (Fig. 4).

We also briefly describe the mechanism of action of the measurement method proposed. The measurement process is regulated by microcontroller $M C$. The binary code of $n$ size 
supplied from port B (PORT B) output, forms the range of reference voltage $U_{0}$ from $0 \mathrm{~V}$ to $10 \mathrm{~V}$ using digital-to-analog converter $D A C$. According to this voltage range, $F$ former generates a short rectangular impulse at its output, along which at trigger $T$ direct output $\tau_{X}$, the level of a logical "1" is generated. The $\tau_{X}=" 1$ " signal arrives at the input of Timer 0 and at the zero bit of port A. On the arrival of a single level ("flag") at the input of port A, the process of quantization of tome interval $\tau_{X}$ starts in Timer 0 using standard-frequency $f_{O}$ impulses from the output of quartz resonator $G$. A reference voltage is also applied through standard resistor $R_{0}$ to the plates of condenser $C_{M}$ of force sensor ES.

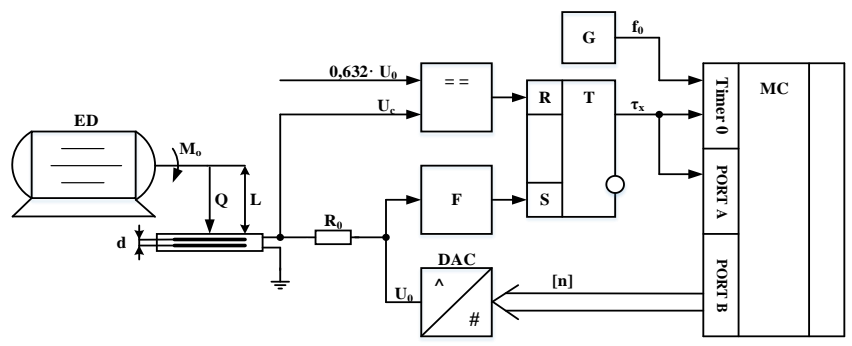

Fig. 4. Structural diagram of measuring channel

The force sensor's condenser $C_{M}$ is charged, and voltage $U_{C}$ at the comparator's input increases according to the exponential law:

$$
U_{C}(t)=U_{o}\left(1-\exp ^{-\frac{t}{\tau_{\mathrm{x}}}}\right) .
$$

At time moment $t=\tau_{X}$

$$
U_{C}(t)=U_{0}\left(1-\exp ^{-1}\right)=0.632 \cdot U_{0}
$$

a short rectangular impulse is also generated at the comparator's output, which zeroes trigger $T$. Quantization process comes to its end in the timer, and the flag in the zero bit of port A acquires the value of a logical zero. The measurement process comes to an end.

Hence, time interval $\tau_{X}=R_{0} C_{M}$ is generated, which is quantized at standard frequency $f_{0}$. During this time interval, the timer's binary counter will count the number $N$ of periods $T_{0}$ at standard frequency $f_{0}$. Based on this equation of the capacity's measuring channel transformation takes the following form:

$$
N=f_{0} R_{0} C_{M} .
$$

By substituting in equation (13), and capacity value $C_{M}$ from (12), we will obtain the function for the transformation of a digital measuring channel of an electric machine's torque

$$
N=f_{0} R_{0} C_{M}=\frac{f_{0} R_{0} \xi_{0} \xi S c}{k M_{0}}=\frac{S_{B K}}{M_{O}},
$$

where $S_{B K}=f_{0} R_{0} \xi_{0} \xi S c / k$ - the sensitivity of the measuring channel torque.

Then the equation of relative quantization error is presented as follows:

$$
\delta_{K}=\frac{1}{N} 100 \%=\frac{M_{0} \cdot 100 \%}{S_{B K}} .
$$

The static characteristics for such a measuring channel are shown in Fig. 5, while the linear dependency between the quantization error and the torque being measured is shown in Fig. 6.

The sensitivity of this torque measuring channel is determined as follows [9]:

$$
S=\frac{d}{d M_{0}} N=-\frac{f_{0} R_{0} \xi_{0} \xi S c}{k} \cdot \frac{1}{M_{0}^{2}}
$$

and varies nonlinearly (quadratically) within the range of possible torque $M_{0}$ variation, which is a disadvantage of such a means of measurement.

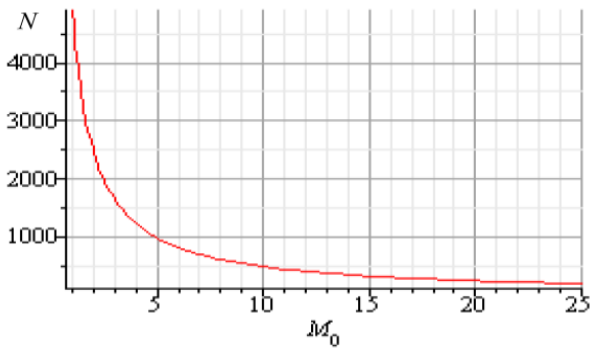

Fig. 5. Static characteristics of measuring channel

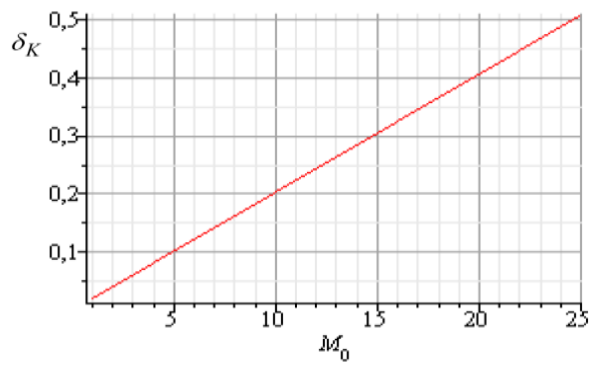

Fig. 6. Dependency between the quantization error and the torque being measured

The lower boundary of torque measurement is restricted by maximum capacity $N_{\max }=2^{n}$ of binary counter CT2. Therefore the equation for the evaluation of the lower measurement boundary will be obtained from transformation equation (14) to be presented in the following form:

$$
N_{O \min }=2^{n}=\frac{f_{0} R_{0} \xi_{0} \xi S c}{k M_{0}}=\frac{S_{B K}}{M_{O}} .
$$

Whereof the value of the lower measurement boundary is determined as follows:

$$
M_{O \min }=\frac{S_{B K}}{2^{n}},
$$

while the graphic dependency between the lower boundary of measurement and the precision of binary counter $M_{O \min }=f(n)$ is shown in Fig. 7.

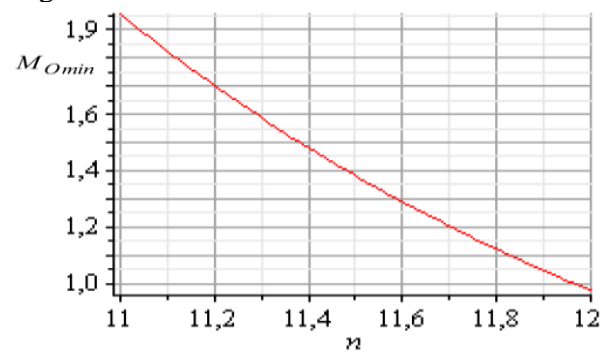

Fig. 7. Dependency between the lower boundary of measurement and the precision of binary counter

The upper measurement boundary is restricted by the standardized value of the quantization error:

$$
\delta_{K H} \leq \frac{M_{\text {omax }} \cdot 100 \%}{S_{B K}} .
$$

Correspondingly, the value of the upper measurement boundary is determined using the following formula:

$$
M_{0 \max }=\frac{\delta_{K H} S_{B K}}{100 \%} .
$$

The graphic dependency between the upper boundary of measurement and standardized value of quantization error $M_{O \min }=f\left(\delta_{K H}\right)$ is shown in Fig. 8 . 


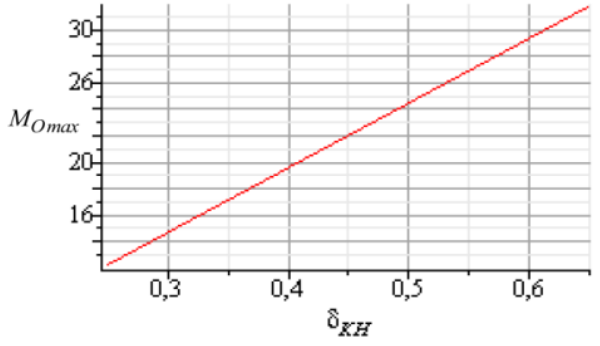

Fig. 8. Dependency between the upper boundary of measurement and standardized value of the quantization error

Within this range of measured value variation (from $M_{\text {Omin }}=1 \mathrm{~N} \cdot \mathrm{m}$ to $M_{0 \max }=25 \mathrm{~N} \cdot \mathrm{m}$ ), the relative quantization error never exceeds the standardized value $\delta_{K H} \leq 0.5 \%$.

We will obtain the formula for the evaluation of the absolute quantization error $\Delta_{K}=\frac{1}{2} \cdot h$, where $h=\frac{M_{0 \max }}{2^{n}}-$ the quantization increment.

For this example, the value of the absolute quantization error is as follows: $\Delta_{K}=\frac{1}{2} \frac{M_{0 \max }}{2^{n}}=\frac{25 \mathrm{~N} \cdot \mathrm{m}}{2 \cdot 2^{12}}=3 \cdot 10^{-3} \mathrm{~N} \cdot \mathrm{m}$.

\section{Conclusions}

1. A formalized method for obtaining analytical dependencies for the evaluation of the main dynamic and static metrological characteristics of a torque measuring channel with a capacitance sensor operating under the regulation of microcontroller was proposed. The static and dynamic characteristics of a typical torque measuring channel based on a capacitance force sensor were evaluated. The dynamic mode of operation of the measuring transformer's movable part is described with a second-order differential equation (7). Its solution was obtained using the Maple 13 mathematical computer program in the form of equation (8), which describes the transient process of the MT's movable part. The results obtained allow the time of the transient process completion to be evaluated (Fig. 2) and the dependency between the value of angular deviation $\varphi$ and applied torque $M_{0}$ to be established.

2. The transformation equation for the static mode of operation based on differential equation (7) was obtained which unambiguously links the initial value of the force sensor's capacity value $C_{M}$ to the input value-rotational torque $M_{O}$. It was established that, in the range of torque variation from 1

\section{D.Sc. Vasyl V. Kukharchuk \\ e-mail: bkuch@ukr.net}

Doctor of Technical Sciences, Professor, Department of Theoretical Electrical Engineering and Electrica Measurements at the Vinnytsia National Technical University, head of the Department of Theoretical Electrical Engineering and Electrical Measurements. Research field: metrology and measuring techniques.

http://orcid.org/0000-0001-9920-2726

\section{Ph.D. Valerii F. Hraniak}

e-mail: titanxp2000@ukr.net

Ph.D. of Technical Sciences, Associate Professor Department of Theoretical Electrical Engineering and Electrical Measurements at the Vinnytsia National Technical University.

Research field: metrology and measuring techniques.

http://orcid.org/0000-0001-6604-6157

to $25 \mathrm{~N} \cdot \mathrm{m}$, the capacity of the sensor under consideration will range from 1 to $10 \mathrm{mcF}$ (Fig. 3), which generates the time constant $\tau_{X}=R_{0} C_{M}$ of the electric circle composed of reference resistor $R_{0}$ and capacity $C_{M}$ of the force sensor.

3. It was proposed to measure time constant $\tau_{X}$ using the hardware and software of microcontroller MC (Fig. 4), the generation of which was based on transformation equation (14) which unambiguously links the output value, number $N$ of periods $T_{0}$ of reference frequency $f_{0}$ and torque $M_{0}$. It was established that the static characteristics of this measuring channel are non-linear (Fig. 5), which is why the quantization error (Fig. 6) at the beginning of the measurement range is minimal, and it grows and acquires its maximum value around the upper measurement boundary. The analytical dependencies for evaluation of the lower (19) and the upper (21) measurement boundaries were obtained. It was demonstrated that the lower measurement boundary is restricted by maximum capacity $N_{\max }=2^{n}$ of the binary counter of microcontroller MC, while the upper one, by the standardized value of the quantization error. 4. It was shown that this approach to the construction of the means of measurement is advisable to use, in particular, during the designing of digital measuring channels of non-electric values with parametric measuring transformers.

\section{References}

[1] Ansari A. A., Deshpande D. M.: Mathematical Model of Asynchronous Machine in MATLAB Simulink. International Journal of Engineering, Science and Technology 2(5), 2010, 1260-1267.

[2] Kukharchuk V. V., Podzarenko V. A.: Mathematical modeling of a measuring converter of asynchronous electric motor starting moment. Second International Scientific and Technical conference on Unconventional electromechanical and electrotechnical systems vol. 2, 1996, 275-280.

[3] Kukharchuk V. V., Vedmitsky Y. G., Hranyak V. F.: Measurement of rotational motion parameters of electromechanical energy converters in transient modes. VNTU, Vinnitsa 2019.

[4] Kukharchuk V. V.: Elements of the theory of control of dynamic parameters of electric machines. Universum-Vinnytsia, Vinnytsia 1998.

[5] Kukharchuk V. V.: Mathematical model of measuring transformation of starting torque with constant input signal. Measuring and computing technology in technological processes 4, 1998, 143-149.

[6] Kyung-Seo K., Sung-Hoon B.: Auto-Measurement of Induction Motor Parameters. Journal of Electrical Engineering and Technology 1(2), 2006, 226232.

[7] Podzharenko V. O., Kukharchuk V. V.: Measurement and computer measuring equipment. UMK VO, Kyiv 1991.

[8] Raghavendra N. V., Krishnamurthy L.: Engineering Metrology and Measurements. Textbook. University Press, Oxford 2013.

[9] Vedmitskyi Y. G., Kukharchuk V. V., Hraniak V. F. et al.: Newton binomial in the generalized Cauchy problem as exemplified by electrical systems. Proc. of SPIE 10808, 2018. 108082M.

\section{Ph.D. Samoil Sh. Katsyv \\ e-mail:katsyv@ukr.net \\ Ph.D. of Technical Sciences, Associate Professor, Department of Theoretical Electrical Engineering and Electrical Measurements at the Vinnytsia National Technical University. \\ Research field: Electrical engineering.}

http://orcid.org/0000-0003-1375-5229

Volodymyr S. Holodyuk
e-mail: vgolodyk@gmail.com
Engineer 3 categories at the LLC KNESS RnD
CENTER.
Research field: Electrical engineering.
http://orcid.org/0000-0002-2449-5488

